\title{
ANÁLISE EXPLORATÓRIO DAS CARACTERÍSTICAS DOS PEDIDOS DE ACESSO À INFORMAÇÃO EM 2018 E 2019
}

\author{
Jackeline Saori Teixeira ${ }^{1}$
}

\begin{abstract}
Resumo
O trabalho busca fazer uma análise exploratória dos pedidos de acesso à informação destinados ao Governo brasileiro, uma vez que a informação é um elemento importante ao que se refere à accountability e poucas pesquisas se debruçam sobre a demanda por informações governamentais pelos cidadãos. Desse modo, busca-se identificar os assuntos abordados pelos pedidos de acesso à informação, assim como as características dos solicitantes. Para a pesquisa foram utilizados os dados dos pedidos realizados por meio do e-SIC ao Poder Executivo Federal. Os dados foram coletados através do sítio online de Acesso à Informação do Governo Federal, que possibilita escolher o ano de referência, sendo escolhidos os dois anos completos mais recentes (2018 e 2019). Encontrou-se que, no período estudado, foram feitos 198611 pedidos de informações pelo e-SIC, sendo abordados 19 temas atribuída pelo Serviço de Informação ao Cidadão de acordo com o Vocabulário Controlado do Governo Eletrônico (agricultura, extrativismo e pesca; ciência, informação e comunicação; comércio, serviços e turismo; cultura, lazer e esporte; defesa e segurança; economia e finanças; educação; governo e política; habitação, saneamento e urbanismo; indústria; informação - gestão, preservação e acesso; justiça e legislação; meio ambiente; pessoa, família e sociedade; previdência social; relações internacionais; saúde; trabalho; transportes e trânsito). Quanto aos solicitantes, verifica-se que são majoritariamente pessoas físicas (121785), sendo que, desse conjunto 0,73\% são de residentes em outros países. As informações levantadas corroboram a ideia de que a busca dos cidadãos por informações não se restringe ao gasto do governo com o funcionalismo, mas perpassam por várias áreas de interesse. Entende-se, também que as contribuições do trabalho são comedidas, dado ser uma análise exploratória, mas ele indica uma dimensão de pesquisa que pode ser explorada. Considera-se que as pesquisas futuras podem se dedicar à investigação pormenorizada do conteúdo dos pedidos relacionado às características dos solicitantes.
\end{abstract}

Palavras-Chave: Accountability; Transparência; Pedidos de Acesso à Informação; Solicitantes; Quinta palavra.

\section{INTRODUÇÃO}

Anterior à promulgação da Lei no 12.527 de 18 de novembro de 2011 (Lei de Acesso à Informação) 2 o acesso do cidadão à informação tutelada pelo governo existia por maneiras diversas, seja a Ouvidoria das organizações, o portal na internet ou as redes sociais. Todavia é com a lei que

\footnotetext{
1 Mestranda no Programa de Pós-Graduação em Ciência Política da Universidade Federal do Paraná, jackeline_st@hotmail.com, ORCID: 0000-0002-8828-2158.

${ }_{2}$ BRASIL. Lei $\mathbf{n}^{\mathbf{0}}$ 12.527, de 18 de novembro de 2011. Regula o acesso a informações previsto no inciso XXXIII do art. $5^{\circ}$, no inciso II do $\S 3^{\circ}$ do art. 37 e no $\S 2^{\circ}$ do art. 216 da Constituição Federal; altera a Lei $n^{\circ} 8.112$, de 11 de dezembro de 1990; revoga a Lei $\mathrm{n}^{\circ} 11.111$, de 5 de maio de 2005, e dispositivos da Lei $\mathrm{n}^{\circ} 8.159$, de 8 de janeiro de 1991; e dá outras providências. 2011. Disponível em: http://www.planalto.gov.br/ccivil_03/_ato20112014/2011/lei/112527.htm. Acesso em: 29 de jun de 2020.
} 
se cria a estrutura e se estipula o padrão para essa modalidade de aproximação. Esse mecanismo possibilita que o cidadão tenha acesso a uma gama significativa de informação com o amparo legal, ou seja a ideia é que a transparência das informações se torna o padrão, enquanto o sigilo a exceção (ALVEZ, 2016)

Episódios recentes na política brasileira apontam para a uma disputa relacionada aos mecanismos. Pode-se citar a da tentativa de modificação da lei que ocorreu em janeiro de 2019, em que o decreto assinado pelo vice-Presidente Hamilton Mourão possibilitava servidores comissionados e dirigentes de fundações, autarquias e empresas públicas imporem sigilo ultrassecreto a dados públicos, atuação que antes era restrita aos chefes do Executivo e membros das Forças Armadas 3. A Câmara dos Deputados votou pela derrubada do decreto e antes que o Senado Federal pudesse votar, o Planalto retirou a matéria. Em 2020, houve a Medida Provisória editada pelo Presidente Jair Bolsonaro que restringia os prazos de resposta da LAI, tal media foi suspensa pelo Supremo Tribunal Federal ${ }_{4}$.

Então, propõe-se fazer uma análise exploratória dos pedidos de acesso à informação destinados ao Governo brasileiro de modo a identificar os assuntos abordados pelos pedidos de acesso à informação, assim como as características dos solicitantes. A fim de atingir tais objetivos se vale da base de dados disponibilizada pelo Sistema Eletrônico do Serviço de Informação ao Cidadão (e-SIC) referente aos anos de 2018 e 2019. A pesquisa está organizada da seguinte maneira: (1) a apresentação da literatura referente à transparência e accountability (2) a apresentação da metodologia, (3) os resultados e, por fim, (4) as conclusões e considerações finais.

\section{REVISÃO DA LITERATURA}

O que se considera por transparência, assim como suas limitações e potencialidades é bastante diverso. De modo resumido Mike Ananny e Kate Crawford (2016, p. 14) entendem que a transparência pode ser entendida por diferentes eixos interpretativos, em um primeiro momento através das informações que são disponibilizadas - se elas são confiáveis sobre desempenho institucional, ou são divulgadas somente nominalmente (e.g. FAIRBANKS, PLOWMAN,

\footnotetext{
${ }_{3}$ G1. Governo permite que servidores comissionados imponham sigilo ultrassecreto a dados públicos. 2019. Disponível em:<https://g1.globo.com/politica/noticia/2019/01/24/governo-delega-competencia-para-decretar-sigilode-informacoes-publicas.ghtml>. Acesso em: 13 fev. 2019. ${ }_{4}$ CORREIO BRAZILIENSE. Moraes suspende ação de Bolsonaro que restringiu acesso à informação. 2020. Disponível em: https://www.correiobraziliense.com.br/app/noticia/politica/2020/03/26/interna_politica,839545/moraes-suspende-acaode-bolsonaro-que-restringiu-acesso-a-informacao.shtml. Acesso em: 29 jun. 2020.
} 
RAWLINS, 2007); quanto ao tipo de prestação de contas que possibilita - encarrega a organização somente a responder ou apresenta o poder de sancionar e exigir compensação por danos(e.g. BERTOT, JAEGER; GRIMES, 2010); em relação a direção em que as informações são disponibilizadas - vertical, caso os agentes internos de diferentes hierarquias consigam observar a conduta uns dos outros, e horizontal se é possível acessar as informações para além dos limites das instituições, que são tuteladas(e.g. MOORE, 2018); a maneira pela qual se configura a transparência organizacional - se o que é realizado é pontual ou se integra à rotina institucional(e.g. FRICK, 2008) e a regularidade pela qual as informações são apresentadas - publicadas retrospectivamente ou sincronicamente(e.g. Baume, Papadopoulos, 2015).

Accountability também é uma palavra polissêmica, visto a característica de der adaptável para cada contexto que é empregada (LYRIO, LUNKES, 2018, p. 2). Alzira Angeli (2017) aponta que o termo passou de estar estritamente relacionada a contabilidade para um direito dos cidadãos de exigirem prestação de contas da atuação dos governantes, a instrumento que permite o exercício do controle social sobre os governos. Além disso, aponta que existe muita divergência quanto a relação entre os dois temas. Uma possível causa é apontada por Daniel Berliner, Benjamin Bagozzi e Brian Palmer-Rubin (2018, p. 223) de que o ceticismo derivaria dos resultados mistos ou inconclusivos dos estudos experimentais recentes sobre se a exposição a novas informações poder mudar o comportamento dos eleitores ou gerar uma maior responsabilização. Assim, os autores sustentam que tais estudos levantam a possibilidade de que o fornecimento de informações não seja o principal obstáculo para sustentar a accountability dos políticos, mas que os déficits no capital humano e na capacidade de ação coletiva sejam os culpados, uma vez que podem afetar não apenas o que as pessoas fazem com a informação, mas também sua demanda por informações relevantes para a responsabilização.

Nesse contexto, os pedidos de acesso à informação podem ser observados por ambas as perspectivas. Quanto a transparência eles ajudam a verificar tanto a transparência vertical quanto a horizontal, uma vez que não há impedimentos legais para que sejam feitas as solicitações. Já quanto a accountability, é possível entender tais demandas tanto como instrumentos para controle social quanto pela própria questão de direito assegurado por lei.

Maurício Lyrio e Rogério Lunkes (2018) fazem uma análise sobre os estudos produzidos sobre transparência, accountability e corrupção no setor público. Os autores encontraram que as pesquisas se concentram em torno de fatores que ajudam a obter transparência $(23,8 \%)$, de reformas do setor público e de accountability $(15,9 \%)$, avaliação de desempenho e accountability / 
transparência $(12,7 \%)$, estratégias anticorrupção $(12,7 \%)$ e implementação de modelos / práticas de accountability $(11,1 \%)$, porém pouca atenção é dada nas demandas de informação (BERLINER, BAGOZZI, PALMER-RUBIN, 2018).

\section{METODOLOGIA}

Os dados foram coletados em fevereiro de 2020 através do sítio online de Acesso à Informação do Governo Federals, onde é possível escolher o ano de consulta, a partir de 2012. Para a presente pesquisa, escolheram-se os dois anos completos mais recentes (2018 e 2019), o que corresponde ao um corpus composto por 80701 solicitantes e 198611 pedidos de informação, como apontado na tabela 1. Decidiu-se utilizar os dados quanto as solicitações e solicitantes de maneira geral, em vez de analisar também os dados compilados sobre os recursos (planilhas diferentes), visto que o objetivo do trabalho é identificar os assuntos abordados pelos pedidos de acesso à informação, assim como as características dos solicitantes.

TABELA 1 - COMPOSIÇÃO DO CORPUS DA PESQUISA

\begin{tabular}{|c|r|r|}
\hline Ano & Solicitantes & \multicolumn{1}{c|}{ Pedidos } \\
\hline 2018 & 42150 & 95517 \\
\hline 2019 & 38551 & 103094 \\
\hline Total & 80701 & 198611 \\
\hline
\end{tabular}

FONTE: O autor com base nos dados do Sistema Eletrônico do Serviço de Informação ao Cidadão (2020).

Como são fornecidas planilhas diferentes sobre os pedidos, os solicitantes e os recursos, cabe fazer a distinção dos conteúdos disponibilizados. Sobre os pedidos, as planilhas apresentadas informações quanto as características de tramite (código identificador, protocolo, órgão destinatário e o órgão superior associado, situação, data de registro, prazo de atendimento, ocorrência de prorrogação ou encaminhamento e identificador do solicitante, meio de origem da solicitação); a solicitação (resumo e conteúdo completo, categoria e subcategoria do pedido, número de perguntas); assim como sobre a resposta (forma de resposta, data da resposta, conteúdo da resposta, tipo de resposta, classificação do tipo de resposta). Já quanto aos solicitantes é informado sobre o tipo de demandante, data de nascimento, sexo, escolaridade, profissão, tipo de pessoa jurídica, país em que o solicitante reside, UF e Município, mas também quanto o pedido consta o ano da solicitação e o identificador da solicitação.

\footnotetext{
s Disponível em: https://esic.cgu.gov.br/sistema/Relatorios/Anual/DownloadDados.aspx. Acesso em: 29 de jun de 2020. 
Cabe mencionar que não são analisadas todas as categorias presentes no banco de dados, houve a preferência daquelas que poderia ajudar a construir um panorama sobre os pedidos de acesso à informação e seus solicitantes. Dentre elas é importante destacar que a classificação quanto a categoria do pedido, assunto que trata o pedido, é feita pelo Vocabulário Controlado do Governo Eletrônico (VCGE). O vocabulário já apresentava esboços desde 2004, mas é a partir da Lei de Acesso à Informação que se difunde dentro do governo, visto que é través dele que se classifica todas as demandas da sociedade pelo Sistemas de Informação ao Cidadão da Controladoria Geral da União. (BRASIL, 2014). Então, a finalidade do vocabulário se torna classificar qualquer conteúdo que não seja classificado por outra forma mais específica de indexação (GAMA, RODRIGUES, 2018).

Para a análise as planilhas de ambos os anos foram coletas, organizadas e reunidas em um banco para os pedidos e outro para os solicitantes, de modo a ser possível trabalhar os dados no Excel. Na seção a seguir são apresentados os dados encontrados.

\section{RESULTADOS}

No que concerne aos solicitantes, o gráfico 1 aponta que o perfil não variou entre os anos estudados em relação ao sexo (composto majoritariamente por homens) ou à escolaridade (maior presença dos grupos conforme maior o grau de escolaridade). Destacam-se que a maior parte das pessoas que decidiram não informar o sexo também não informaram a escolaridade. A última categoria (Não se aplica) é referente aos pedidos feitos por pessoas jurídicas em ambos os anos, o que permite identificar a presença majoritária de requisitantes que utilizaram os dados pessoais para fazer os pedidos. 


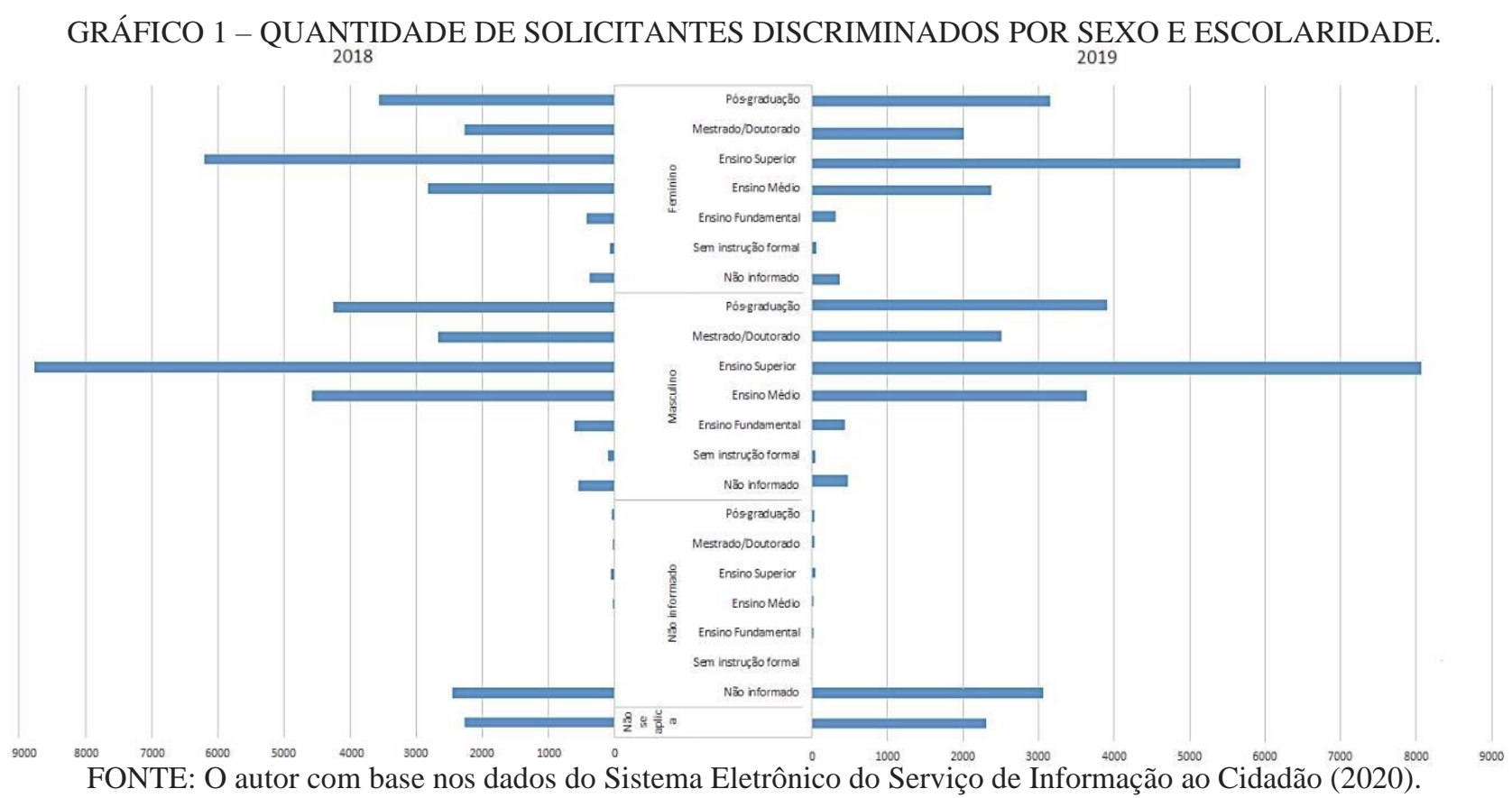

No que concerne a localização dos solicitantes, a tabela 2 permite observar que em 2018 a região que concentrou maior quantidade de solicitantes foi a Sudeste, seguida pela Nordeste, Centro-Oeste, Sul, "Não informado" (quando é marcado Brasil, mas não se especifica o Estado ou Município), Norte e "Não se aplica” (outros países). Contudo é possível perceber que em 2019 ocorre uma movimentação da categoria "Não informado" que passa para a segunda posição.

TABELA 2 - LOCALIZAÇÃO DOS SOLICITANTES.

\begin{tabular}{|l|r|r|r|}
\hline Região de & Ano & Total \\
\cline { 2 - 4 } solicitação & 2018 & 2019 & \\
\hline Centro-Oeste & 5796 & 4462 & 10258 \\
\hline Nordeste & 6828 & 5074 & 11902 \\
\hline Norte & 2244 & 1873 & 4117 \\
\hline Sudeste & 18402 & 1474 & 33145 \\
& & 3 & \\
\hline Sul & 5302 & 4390 & 9692 \\
\hline Não informado & 3487 & 7712 & 11199 \\
\hline Não se aplica & 91 & 297 & 388 \\
\hline Total & 42150 & 3855 & 80701 \\
& & 1 & \\
\hline
\end{tabular}

FONTE: O autor com base nos dados do Sistema Eletrônico do Serviço de Informação ao Cidadão (2020).

Um aprofundamento que se pode fazer quanto ao tipo de solicitante (pessoa física ou jurídica) e a localização é apresentado na tabela 3. Além de indicar que a maioria dos solicitantes 
são brasileiros $(99,25 \%)$, os dados demonstram houve uma menor diversidade de países em que os solicitantes residem (45) em comparação com 2018 (53).

TABELA 3 - PAÍS EM QUE RESIDE POR TIPO DE SOLICITANTE NOS ANOS DE 2018 E 2019.

\begin{tabular}{|c|c|c|c|}
\hline \multirow{2}{*}{ Tipo de solicitante } & \multicolumn{2}{|l|}{ Ano } & \multirow{2}{*}{ Total } \\
\hline & 2018 & 2019 & \\
\hline \multirow[b]{2}{*}{ Pessoa Física } & 39885 & 3623 & 7612 \\
\hline & 5 & 8 & 3 \\
\hline África do Sul & 0 & 2 & 2 \\
\hline Alemanha & 16 & 14 & 30 \\
\hline Andorra & 1 & 0 & 1 \\
\hline Angola & 1 & 0 & 1 \\
\hline Argentina & 11 & 12 & 23 \\
\hline Austrália & 3 & 7 & 10 \\
\hline Áustria & 1 & 3 & 4 \\
\hline Bélgica & 1 & 2 & 3 \\
\hline Benin & 1 & 0 & 1 \\
\hline Bolívia & 4 & 3 & 7 \\
\hline Brasil & $\begin{array}{r}39580 \\
0\end{array}$ & $\begin{array}{r}35945 \\
5\end{array}$ & $\begin{array}{r}7552 \\
5\end{array}$ \\
\hline Brunei & 2 & 0 & 2 \\
\hline Cabo Verde, República de & 2 & 0 & 2 \\
\hline Canadá & 6 & 10 & 16 \\
\hline Cazaquistão, República do & 2 & 0 & 2 \\
\hline Chile & 10 & 10 & 20 \\
\hline China, República Popular da & 0 & 2 & 2 \\
\hline Cingapura & 3 & 0 & 3 \\
\hline Colômbia & 8 & 8 & 16 \\
\hline Coréia, República da & 0 & 1 & 1 \\
\hline Costa Rica & 0 & 1 & 1 \\
\hline Dinamarca & 0 & 1 & 1 \\
\hline El Salvador & 1 & 1 & 2 \\
\hline Emirados Árabes Unidos & 1 & 0 & 1 \\
\hline Equador & 0 & 3 & 3 \\
\hline Escócia & 1 & 0 & 1 \\
\hline Espanha & 17 & 12 & 29 \\
\hline Estados Unidos & 63 & 63 & 126 \\
\hline Finlândia & 2 & 1 & 3 \\
\hline França & 12 & 15 & 27 \\
\hline Grã-Bretanha & 1 & 1 & 2 \\
\hline Guiana & 1 & 0 & 1 \\
\hline Haiti & 1 & 2 & 3 \\
\hline Holanda (Países Baixos) & 1 & 3 & 4 \\
\hline Honduras & 0 & 1 & 1 \\
\hline Hong Kong, Região Adm. Especial & 0 & 1 & 1 \\
\hline
\end{tabular}




\begin{tabular}{|c|c|c|c|}
\hline Hungria, República da & 1 & 0 & 1 \\
\hline Índia & 0 & 2 & 2 \\
\hline Inglaterra & 5 & 3 & 8 \\
\hline Iraque & 1 & 0 & 1 \\
\hline Irlanda & 2 & 2 & 4 \\
\hline Israel & 3 & 3 & 6 \\
\hline Itália & 6 & 8 & 14 \\
\hline Japão & 8 & 6 & 14 \\
\hline Líbano & 1 & 1 & 2 \\
\hline Lituânia, República da & 2 & 0 & 2 \\
\hline Malta & 0 & 1 & 1 \\
\hline México & 8 & 8 & 16 \\
\hline Moçambique & 2 & 0 & 2 \\
\hline Nicarágua & 1 & 0 & 1 \\
\hline Panamá & 2 & 0 & 2 \\
\hline Paraguai & 2 & 2 & 4 \\
\hline Peru & 5 & 11 & 16 \\
\hline Polônia, República da & 2 & 2 & 4 \\
\hline Portugal & 40 & 41 & 81 \\
\hline Reino Unido & 21 & 12 & 33 \\
\hline Rússia & 1 & 0 & 1 \\
\hline Suécia & 4 & 1 & 5 \\
\hline Suíça & 5 & 3 & 8 \\
\hline Turquia & 1 & 0 & 1 \\
\hline Uruguai & 4 & 4 & 8 \\
\hline Venezuela & 5 & 3 & 8 \\
\hline Virgens, Ilhas (Britânicas) & 0 & 1 & 1 \\
\hline Pessoa Jurídica & 2265 & 2313 & 4578 \\
\hline Brasil & 2261 & 2309 & 4570 \\
\hline Chile & 0 & 1 & 1 \\
\hline Estados Unidos & 1 & 2 & 3 \\
\hline França & 0 & 1 & 1 \\
\hline Holanda (Países Baixos) & 1 & 0 & 1 \\
\hline Letônia, República da & 1 & 0 & 1 \\
\hline Suíça & 1 & 0 & 1 \\
\hline Total & $\begin{array}{r}4215 \\
0\end{array}$ & $\begin{array}{r}3855 \\
1\end{array}$ & $\begin{array}{r}8070 \\
1\end{array}$ \\
\hline
\end{tabular}

FONTE: O autor com base nos dados do Sistema Eletrônico do Serviço de Informação ao Cidadão (2020).

A partir dos dados pode-se verificar que o padrão dos solicitantes é masculino, com ensino médio ou mais, residente no Brasil e que utiliza os dados pessoas para solicitar as informações. Esses dados mostram que os solicitantes apresentam perfil diferente do que a população brasileira em geral, visto que no censo de 2010 ${ }_{6}$ mostra que a maior parte da população é feminina, com 
educação até o ensino médio.

Quanto às solicitações, verifica-se que os pedidos versaram sobre 19 temas diferentes, como é apresentado na tabela 5. As categorias mais mencionadas em ambos os anos são "Educação", "Governo e Política", "Ciência, Informação e Comunicação" e "Economia e Finanças" respectivamente. Já os menos mencionados são "Relações Internacionais", "Previdência Social" e "Informação - Gestão, preservação e acesso", os dois últimos com somente um pedido cada em 2018.

TABELA 5 - CATEGORIAS DOS PEDIDOS APRESENTADOS EM 2018 E 2019.

\begin{tabular}{|l|r|r|r|}
\hline \multirow{2}{*}{ Categoria do pedido } & Ano & \multirow{2}{*}{ Total } \\
\cline { 2 - 3 } & 2018 & 2019 & \\
\hline Agricultura, extrativismo e pesca & 2840 & 4456 & 7296 \\
\hline Ciência, Informação e Comunicação & 11660 & 14010 & 25670 \\
\hline Comércio, Serviços e Turismo & 2632 & 2038 & 4670 \\
\hline Cultura, Lazer e Esporte & 1073 & 888 & 1961 \\
\hline Defesa e Segurança & 2348 & 2969 & 5317 \\
\hline Economia e Finanças & 11103 & 9053 & 20156 \\
\hline Educação & 17501 & 17777 & 35278 \\
\hline Governo e Política & 13998 & 17070 & 31068 \\
\hline Habitação, Saneamento e Urbanismo & 1138 & 627 & 1765 \\
\hline Indústria & 3863 & 4772 & 8635 \\
\hline Informação - Gestão, preservação e acesso & 1 & 0 & 1 \\
\hline Justiça e Legislação & 1790 & 1874 & 3664 \\
\hline Meio ambiente & 1611 & 2363 & 3974 \\
\hline Pessoa, família e sociedade & 4421 & 5953 & 10374 \\
\hline Previdência social & 1 & 0 & 1 \\
\hline Relações internacionais & 55517 & 10309 & 49861 \\
\hline Saúde & 8457 & 10345 & 18802 \\
\hline Trabalho & 6123 & 4217 & 10340 \\
\hline Transportes e trânsito & 4457 & 4104 & 8561 \\
\hline Total & 500 & 1078 \\
\hline
\end{tabular}

FONTE: O autor com base nos dados do Sistema Eletrônico do Serviço de Informação ao Cidadão (2020).

Os temas mais citados podem ser compreendidos no contexto temporal em que houve o período eleitoral (2018) e o primeiro ano de mandato do Executivo Federal, sendo que a agenda econômica foi muito enfatizada nesse período. A agenda quanto a educação estava destaque desde governos anteriores, mas especialmente quanto a reforma do ensino médio de 2016, que culminou 
na lei $\mathrm{n}^{\circ} 13.415$ de $2017_{7}$, mas a chapa vitoriosa na eleição sustentava um posicionamento favorável à educação básica em detrimento do ensino superior, sendo que em 2019 houve queda no investimento do setor. assim como a apresentação do projeto "Future-se" que foi rejeitado pela maioria das universidades 9 .

O contexto ajuda a compreender parte do fenômeno, mas como a pesquisa não analisa o exato conteúdo das solicitações é difícil afirmar em que medida ele está relacionado de fato com as requisições. Contudo, tais dados podem ser observados ainda como indicadores da agenda dos solicitantes que apresentam como características marcante escolaridade superior à média brasileira.

\section{CONCLUSÃO E CONSIDERAÇÕES FINAIS}

Encontrou-se que o padrão dos solicitantes é masculino, com ensino médio ou mais, residente no Brasil e que utiliza os dados pessoas para solicitar as informações. Os temas mais frequentes são "Educação", "Governo e Política", "Ciência, Informação e Comunicação" e "Economia e Finanças" respectivamente, enquanto os menos elencados são "Relações Internacionais", "Previdência Social” e "Informação - Gestão, preservação e acesso".

Os dados demonstram que realizar um pedido de acesso à informação não é algo corriqueiro, que qualquer cidadão faça, por mais que haja a adoção dos mecanismos previstos em lei que garantem o acesso dos cidadãos, principalmente, visto que são estipulados meios físicos e digitais para possibilitar o efetuar o fornecimento de informações, assim como o processamento das demandas. Esse contexto retoma a discussão não somente relacionada à exclusão digital (MARQUES, 2014), mas também sobre como são realizadas as atividades de transparência governamental direcionadas à população (BERTOT, JAEGER, GRIMES, 2012).

\footnotetext{
${ }_{7}$ BRASIL. Lei $\mathbf{n}^{\mathbf{0}}$ 13.415, de 16 de fevereiro de 2017. Altera as Leis $\mathbf{n}^{\circ}$ 9.394, de 20 de dezembro de 1996 , que estabelece as diretrizes e bases da educação nacional, e 11.494, de 20 de junho 2007, que regulamenta o Fundo de Manutenção e Desenvolvimento da Educação Básica e de Valorização dos Profissionais da Educação, a Consolidação das Leis do Trabalho - CLT, aprovada pelo Decreto-Lei $n^{\circ} 5.452$, de $1^{\text {o }}$ de maio de 1943 , e o Decreto-Lei $n^{\circ} 236$, de 28 de fevereiro de 1967; revoga a Lei n ${ }^{\circ} 11.161$, de 5 de agosto de 2005; e institui a Política de Fomento à Implementação de Escolas de Ensino Médio em Tempo Integral. 2017. Disponível em: http://www.planalto.gov.br/ccivil_03/_ato2015-2018/2017/lei/113415.htm. Acesso em: 29 de jun de 2020.

8 AYRES, Marcela. Gastos com educação têm menor valor em 4 anos em governo Bolsonaro. UOL. 2019. Disponível em: https://economia.uol.com.br/noticias/reuters/2020/01/31/gastos-com-educacao-tem-menor-valor-em-4-anos-emgoverno-bolsonaro.htm. Acesso em: 29 de jun de 2020.

9 CAFARDO, Renata; MENGUE, Priscila. Maioria das universidades federais rejeita Future-se, do MEC. O Estado de S. Paulo. 2019. Disponível em: https://educacao.estadao.com.br/noticias/geral,maioria-das-universidades-federaisrejeita-future-se,70003024425. Acesso em: 29 de jun de 2020.
} 
Os mecanismos de transparência acabam por refletir a desigualdade brasileira, pois por mais que haja um aparato legal estruturado que reforce a relação entre Estado e sociedade, a maior parte da população ainda não acessa tais estruturas, isso independentemente do meio (presencial ou online). O maior acesso da população de escolaridade mais alta, por sua vez, faz retomar o argumento de Daniel Berliner, Benjamin Bagozzi e Brian Palmer-Rubin (2018) quanto ao déficit de capital humano e na capacidade de ação coletiva. Tal perspectiva em conjunto com os achados de Paulo Ferracioli, de que os jornalistas correspondiam a 2,7\% dos solicitantes de informação em 2017, corroboram para a ideia de que tais mecanismo, no momento não alcançaram os patamares de generalizados de controle da coisa pública, seja dentre os cidadãos, seja entre os membros da imprensa, devido a motivos que a presente pesquisa não tem como alçar. Cabe questionar se o modelo de democracia a qual estão associadas tais ferramentas pressupõe o comportamento vigilante da população de forma generalizada ou se esperava a interação de poucos com tais ferramentas.

O estudo apresenta limitações quanto a profundidade da análise dos dados, se atendo somente a uma primeira exploração do material. Ademais, existe um problema interno ao banco, pois a classificação quanto aos tópicos abordados, por mais que o VCGE esteja estruturado e passe por revisões periódica, Janyluce Gama e Georgete Rodrigues (2018, p. 34) apontam que não teria ocorrido até o momento nenhum treinamento aos gestores públicos no uso dessa ferramenta, sendo que sua operacionalização como ferramenta de gestão está limitada aos materiais publicados pela Controladoria-Geral da União, o que pode ser uma limitação para operacionalização da Lei de Acesso à Informação por meio do sistema e-SIC.

Análises futuras podem explorar mais a fundo o conteúdo dos pedidos de acesso à informação para identificar o que exatamente procuram e desse modo confrontar os dados do VCGE, assim como verificar a associação entre os conteúdos e as características dos requerentes. Ademais, pode-se investigar os fatores que influenciam na agenda nos temas solicitados, seja através de parâmetros históricos, seja pela cobertura da imprensa.

\section{REFERÊNCIAS}

ALVES, Marília Souza Diniz. Do sigilo ao acesso: análise tópica da mudança de cultura. Revista do Tribunal de Contas do Estado de Minas Gerais. Belo Horizonte, v. 1, n. 1, p. 120-134, 2012. 
ANGELI, Allzira. Accountability e internet numa perspectiva comparada: A atuação digital das controladorias públicas na América Latina. 2017. Dissertação (Mestrado em Ciência Política) - Setor de Ciência Humanas da Universidade Federal do Paraná, Curitiba.

BAUMEA, Sandrine; PAPADOPOULOS, Yannis. Transparency: from Bentham's inventory of virtuous effects to contemporary evidence-based skepticism. Critical Review of International Social and Political Philosophy, 2015.

BERTOT, John C.; JAEGER, Paul T.; GRIMES, Justin M. Using ICTs to create a culture of transparency: E-government and social media as openness and anti-corruption tools for societies. Government Information Quarterly, v. 27, n. 3, p. 264-271, 2010.

BERTOT, Jhon Carlo; JAEGER, Paul; GRIMES, Justin. Promoting transparency and accountability through ICTs, social media, and collaborative e-government. Transforming Government: People, Process and Policy, v. 6 n. 1, p. 78-91. 2012. doi: https://doi.org/10.1108/17506161211214831

BRASIL. Ministério do Planejamento, Orçamento e Gestão. Secretaria de Logística e Tecnologia da Informação VCGE Voabulário de Governo Eletrônico. Brasília : Ministério do Planejamento, Orçamento e Gestão. Secretaria de Logística e Tecnologia da Informação, 2014.

FAIRBSANS, Jenille; PLOWMAN, Kenneth D.; RAWLINS, Brad L. Transparency in government communication. Journal of Public Affairs, v. 7, n. 10, p. 23-37, 2007.

FERRACIOLI, Paulo. Jornalismo como agente da Lei de Acesso à Informação (L.A.I.): uma comparação entre pedidos de jornalistas e publicações na imprensa sobre a lei. In: X Congreso Latinoamericano de Ciencia Política, 2019, Monterrey. Anais ..., 2019.

FRICK, Maria. Translucent States: Political Mediation of E-Transparency. International Journal of Electronic Government Research, v. 4, n. 3, p. 81-102, 2008.

GAMA, Janyluce Rezende; RODRIGUES, Georgete Medleg. O vocabulário controlado do Governo Eletrônico: contribuições e limites na implementação da Lei de Acesso à Informação no Brasil. Em Questão, v. 24, n. 1, p. 12-40, 2018. doi: http://dx.doi.org/10.19132/1808-5245241.12$\underline{40}$

LYRIO, Maurício; LUNKES, Rogério. Thirty Years of Studies on Transparency, Accountability and Corruption in the Public Sector: The State of the Art and Opportunities for Future Research. Public Integity, v. 20, n. 1, 2018.

MARQUES, Francisco Paulo Jamil Almeida. Democracia online e o problema da exclusão digital. Intexto, n. 30, 2014.

MOORE, Sarah. Towards a Sociology of Institutional Transparency: Openness, Deception and the Problem of Public Trust. Sociology, v. 52, n. 2, p. 416-430, 2018. 